\title{
Farm Profitability as a Driver of Spatial Spillovers: The Case of Somatic Cell Counts on Wisconsin Dairies
}

\author{
Theodoros Skevas ${ }^{1 \star}$ (D), Ioannis Skevas ${ }^{2}$ (D) and Victor E. Cabrera ${ }^{3}$ (D) \\ ${ }^{1}$ Division of Applied Social Sciences, University of Missouri, Columbia, MO, USA, ${ }^{2}$ Department of Food \\ Business and Development, University College Cork, Cork, Ireland and ${ }^{3}$ Department of Dairy Science, \\ University of Wisconsin, Madison, WI, USA \\ *Corresponding author. Email: skevast@umsystem.edu
}

(Received 2 May 2020; revised 30 October 2020; accepted 2 November 2020)

\begin{abstract}
We hypothesize that spatial spillovers among neighboring farms are not only driven by spatial proximity, but also by farm profitability considerations. This hypothesis is tested by examining the role of spatial spillovers in shaping somatic cell counts (SCC) on Wisconsin dairy farms. Results show that neighborhood links defined both in terms of geographic proximity and farm profitability give rise to spatial spillovers that affect SCC. Significant differences in the estimated spatial spillovers are observed when defining the neighborhood space in terms of both farm profitability and geographic proximity as opposed to geographic proximity alone, with the data favoring the former specification.
\end{abstract}

Key Words: dairy farms; somatic cell count; spatial lag of X model; spatial spillovers

\section{Introduction}

Spatial spillovers are defined as the impact that a characteristic or action of a unit $i$ has on the outcomes, decisions, or actions of other units $j$ (Halleck Vega and Elhorst 2015). ${ }^{1}$ The role of spatial spillovers on farm-level behavior and performance is a topic of increasing interest in agricultural economics research. Empirical studies in this area focus on technology adoption (Läpple et al. 2017; Skevas, Skevas, and Swinton 2018), farm survival (Storm, Mittenzwei, and Heckelei 2014), market participation (Holloway and Lapar 2007), and farm efficiency (Areal, Balcombe, and Tiffin 2012; Skevas 2020), and provide evidence of the importance of considering spatial spillovers when modeling farm-level behavior and performance.

To account for spatial spillovers in decision-making models, one must first define the neighborhood space and specify the strength of interaction between neighboring units. In the context of farming, living near another farmer is known to increase the

\footnotetext{
${ }^{1}$ Depending on the nature of the study, units can be households, firms, regions, countries and so on.

(c) The Author(s) 2021. This is an Open Access article, distributed under the terms of the Creative Commons Attribution licence (http://creativecommons.org/licenses/by/4.0/), which permits unrestricted re-use, distribution, and reproduction in any medium, provided the original work is properly cited.
} 
likelihood of a social link (Maertens and Barrett 2012), implying that geographic proximity should be taken into account when specifying neighborhood relations. Geographic proximity, although important, may not be the only driver of spatial interaction among neighboring farms. For instance, farmers may choose other farmers to mimic with whom they share common personal or professional characteristics (e.g., education, membership in a professional association); the latter can be referred to as homophilic neighbors, using the terminology of Rogers (2010). Another possibility is that farmers adjust their practices to align with those of their economically successful neighbors, as previous empirical studies have shown to be the case in both developing (Conley and Udry 2010) and developed countries (Chatzimichael, Genius, and Tzouvelekas 2014). However, despite the obvious role that socioeconomic factors can play in giving rise to spatial spillovers in farming, past spatial econometric studies of farm behavior and performance have largely ignored such effects and mainly used geographic criteria to define the neighborhood space. One notable exception is the study by Läpple et al. (2017) who, in an effort to overcome a missing neighbor problem, constructed a spatial weight matrix using census data on dairy livestock intensity at the electoral division level and geographic proximity among the sample farms.

Against this background, the main objective of this article is to assess the importance and role of economic factors, and more specifically farm profitability, in giving rise to spatial spillovers. More precisely, we examine whether spatial spillovers are driven by physical proximity to farms of a higher profit level. Our interest in this research question is driven by the fact that farmers tend to imitate the practices of their economically successful neighbors (Chatzimichael, Genius, and Tzouvelekas 2014; Conley and Udry 2010). We apply our modeling framework to examine the role of spatial spillovers in shaping somatic cell counts (SCC) of dairy farms. SCC, which is the number of leukocytes in milk, is an indicator of subclinical mastitis in dairy cattle (Hogeveen, Steeneveld, and Wolf 2019). Mastitis (clinical or subclinical) is the most economically important disease in the dairy industry, causing, among others, milk yield losses, higher workload for the producers, involuntary culling of cows, and increased veterinary and medical expenses (Halasa et al. 2007). Moreover, milk buyers often impose price penalties to farmers failing to meet imposed milk quality standards, including standards on SCC levels (Volpe et al. 2015). Therefore farmers, have several reasons to decrease the incidence of mastitis on their farms.

In the context of mastitis, spatial spillovers are important for the following reasons. First, some farmers may lack the knowledge to effectively prevent and control mastitis (Kuiper et al. 2005). Such farmers are potentially inclined to seek technical information from neighboring farmers that are more successful in improving udder health. Second, when the cost of veterinary intervention is high, as might be the case with mastitis control, some farmers are shown to consider their peers' experiences when deciding how to control animal diseases (Alarcon et al. 2014). Therefore, it is important to account for spatial spillovers when modeling the incidence of mastitis at the farm-level.

This article makes two contributions to the literature. First, we are the first to examine the role of farm profitability as a driver of spatial spillovers between neighboring farms. Second, this article extends previous studies on the determinants of SCC (Dong, Hennessy, and Jensen 2012; Haskell et al. 2009; Volpe et al. 2015) by investigating the role of spatial spillovers in shaping SCC. The rest of the paper is organized as follows. Section "Methodology" presents the methodology employed, while section "Data and Empirical Issues" describes the data used in the present analysis. Results are presented in Section "Results", and Section "Conclusions" concludes. 


\section{Methodology}

We employ a spatial lag of X model (SLX) to assess the existence and role of spatial spillovers in shaping SCC of dairy farms. We choose the SLX model because it is the simplest and most straightforward way (both in terms of estimation and interpretation) of producing such spillovers without imposing a priori restrictions on the magnitude of spillover effects (Halleck Vega and Elhorst 2015). ${ }^{2}$ The SLX model can be written as follows:

$$
\mathrm{SCC}_{t}=\mathrm{X}_{t} \boldsymbol{\beta}+\mathrm{WX}_{t} \boldsymbol{\gamma}+\boldsymbol{\alpha}+\boldsymbol{\epsilon}_{t}
$$

where SCC is an $N \times 1$ vector of log-transformed farm-specific somatic cell count scores observed in period $t$ (with $N$ being the number of observations), $X$ is an $N \times K$ matrix of $K$ farm-specific characteristics that may affect SCC, $W$ is an $N \times N$ spatial weighting matrix (defined below), $\boldsymbol{\beta}$ and $\boldsymbol{\gamma}$ are the associated $K \times 1$ vectors of parameters to be estimated, $\boldsymbol{\alpha}$ is an $N \times 1$ vector of unobserved farm-specific heterogeneity effects, and $\epsilon$ is an $N \times 1$ vector of disturbance terms. The $W X$ term, which is referred to in spatial econometrics as "the spatial lags of the explanatory variables", represents the characteristics and production decisions of neighboring farms. Therefore, $\gamma$, which is known in spatial econometrics as the "indirect or spillover effect", captures how a farm's level of mastitis changes when a particular explanatory variable in neighboring farms increases. On the other hand, $\boldsymbol{\beta}$ captures the so-called "direct effect", i.e. the change in a farm's level of mastitis attributable to an increase in an explanatory variable of that farm itself. Note that if $\gamma=0$, the model in (equation 1) reduces to a non-spatial regression model that does not allow any spatial spillovers to affect a farm's SCC level. Such a model is also estimated for comparison purposes. Finally, the Hausman test is used to check whether $\alpha$ represents a fixed or a random effect.

We note here that more spatial econometric models are able to produce spatial spillover effects without imposing restrictions on the magnitude of these effects in advance. As mentioned above, the SLX model is the simplest of these flexible models (Halleck Vega and Elhorst 2015). A comparison of different spatial econometric models is out of the scope of the current study and is left for future research.

\section{Spatial Weight Matrix Specifications}

In order to estimate the SLX model we need to specify a spatial weighting matrix $W$, whose elements reflect the intensity of the interdependence between neighboring farms. Two different spatial weight matrix specifications are considered in this article.

The first specification is one in which neighborhood is defined only in the dimension of geographic space. More specifically, we use an inverse distance matrix $W^{i n v}$ that takes the following form:

$$
\left(W^{i n v}\right)_{i j}=\left\{\begin{array}{cc}
1 / d_{i j}, & \text { if } \mathrm{i} \neq \mathrm{j}, \text { and } d_{i j} \leq d^{*} \\
0, & \text { otherwise }
\end{array}\right.
$$

where $d_{i j}$ is the Eucledian distance between two farms $i$ and $j$ and $d^{*}$ is the minimum distance requirement or cut-off. Following Skevas and Grashuis (2020) and Marasteanu

\footnotetext{
${ }^{2}$ In contrast to other studies (e.g., Volpe et al. (2015)), we do not use a quantile regression to model SCC. This is because (a) SCC consists of continuous values (not count data) and follows approximately a normal distribution, and (b) this article's goal is to examine whether spatial spillovers affect SCC and not whether they affect SCC differently for farms with different SCC levels.
} 
and Jaenicke (2016), we set $d^{*}$ to the minimum distance that guarantees at least one neighbour to each farmer. The diagonal elements of the inverse distance matrix are set equal to zero since no farm can be viewed as its own neighbor. Finally, following common practice, the inverse distance matrix is scaled by dividing it by its maximum eigenvalue (Elhorst 2001; Kelejian and Prucha 2010). Note that the inverse distance matrix places a higher weight on closer than more distant neighbors, it is in line with Tobler's First Law of Geography that near units are more likely to be related than distant ones (Tobler 1970), and it is commonly used in studies that examine the role of peer effects in farm decision-making and performance (e.g., Läpple et al. 2017; Skevas, Skevas, and Swinton 2018).

The second spatial weights matrix specification, assumes that farmers follow other farmers close to them both geographically and with higher farm profit levels. This matrix is constructed as the Hadamard product ${ }^{3}$ of the inverse distance matrix (before normalization) defined in equation 2 and a time-varying matrix that reflects the economic distance between a given farmer and his/her more economically successful neighbors ${ }^{4}: W_{t}^{i n v \_s}=W^{i n v} \circ W_{t}^{s}$, where

$$
\left(W_{t}^{s}\right)_{i j}=\left\{\begin{array}{cc}
\frac{\left|\tilde{\Pi}_{i t}-\tilde{\Pi}_{j t}\right|}{\operatorname{Max}\left\{\left|\tilde{\Pi}_{i t}-\tilde{\Pi}_{1 t}\right|,\left|\tilde{\Pi}_{i t}-\tilde{\Pi}_{2 t}\right|, \ldots,\left|\tilde{\Pi}_{i t}-\tilde{\Pi}_{t t}\right|\right\}} & \text { if } i \neq j \text { and } \tilde{\Pi}_{i t}<\tilde{\Pi}_{j t}, j=1, \ldots, J \\
0, & \text { otherwise }
\end{array}\right.
$$

where $\tilde{\Pi}_{i t}$ is the inverse hyperbolic sine transformation of profit per cow of farmer $i$ at time $t$ (see section "Results" for the reasoning behind this transformation), $|\cdot|$ denotes absolute value, and $J$ is the number of observations in the sample less the farm under investigation (i.e., $i$ ). In $W_{t}^{s}$, the absolute difference in profit levels between two farmers $i$ and $j$ is divided by the maximum absolute difference in profit between farmer $i$ and all other farmers in the sample. This procedure allows weights in $W_{t}^{s}$ to range from close to zero (little interaction or influence between two farmers) to one (maximum interaction or influence between two farmers), facilitating influence contrasts between farmer $i$ and his/her more economically successful neighbors. This matrix was then multiplied (in a Hadamard way) by the inverse distance matrix to assure that a higher weight is assigned to the closest (in distance terms) more profitable neighbors. Hence, the final matrix $W_{t}^{\text {inv_s }}$ assumes that farmers follow other farmers close to them both geographically and with higher profit levels. The latter assumption is motivated by the finding that farmers, both in developing (Conley and Udry 2010) and developed countries (Chatzimichael, Genius, and Tzouvelekas 2014), tend to imitate the behavior of more successful farmers. Following Elhorst (2001) and Kelejian and Prucha (2010), each element of $W_{t}^{i n v s}$ is divided by its largest characteristic root. An example showing how the $W_{t}^{i n \_s}$ matrix works is provided in the supplementary material.

To the best of our knowledge, the employed approach to construct a spatial weight matrix that captures decision makers' proximity to more economically successful peers (i.e., $W_{t}^{i n v-s}$ ) is novel and no implementations of such a matrix have been identified previously. We note, however, that the use of spatial weights that are based on both geographic contiguity and economic distance (using different economic variables and

\footnotetext{
${ }^{3}$ The Hadamard product is an element-by-element product of two matrices.

${ }^{4}$ In their study examining the spillover effects of government spending among 30 Chinese provinces, $\mathrm{Qu}$, Wang, and Lee (2016) also combine a time-varying matrix based on economic linkages and a timeinvariant matrix based on geographic distance.
} 
applied to non-agricultural settings) is not uncommon in applied spatial econometrics analysis (see for e.g., Delgado, Lago-Peñas, and Mayor 2018; Qu, Wang, and Lee 2016).

\section{Endogeneity of the Spatial Economic Weight Matrix}

Spatial weight matrices that are based on a theory of distance, such as our inverse distance matrix above, are considered exogenous to any system (Getis 2009). When spatial weights are determined by economic variables, such as the profit variable in the case of $W_{t}^{i n s_{-} s}$ above, then the exogeneity assumption of the spatial weight matrix will likely be violated ( $\mathrm{Qu}$, Wang, and Lee 2016). In our case, farm profitability and SCC might be affected by the same time-varying factors, such as hired labor quality, and cleanliness of the housing, bedding, and milking equipment, which are hard to observe or measure. As a result, it is very likely that $W_{t}^{i n v-s}$ is correlated with the error term in the SCC model, leading to endogeneity bias. ${ }^{5}$

To deal with the potential endogeneity problem, we use a two-stage instrumental variables (2SIV) approach, which was developed by Qu, Wang, and Lee (2016). In the first step, we estimate the following regression model:

$$
\tilde{\Pi}_{t}=Z_{t} \boldsymbol{\delta}+\boldsymbol{\eta}+\boldsymbol{\xi}_{t}
$$

where $\tilde{\Pi}$ is an $N \times 1$ vector of the inverse hyperbolic sine transformation of profits per cow observed in period $t, Z$ is an $N \times L$ matrix of instruments, $\eta$ is an $\mathrm{N}$-dimensional vector of unobserved farm-specific heterogeneity effects, ${ }^{6}$ and $\xi$ is a $\mathrm{N}$-dimensional vector of disturbance terms. The residuals from estimating equation 4 are then included in the following SLX model:

$$
\mathrm{SCC}_{t}=\mathrm{X}_{t} \boldsymbol{\beta}+\mathrm{W}_{t}^{\text {inv }{ }^{s}} \mathrm{X}_{t} \boldsymbol{\gamma}+\boldsymbol{\xi}_{t} \boldsymbol{\phi}+\boldsymbol{\alpha}+\boldsymbol{u}_{t}
$$

where $\phi$ is a parameter to be estimated, $\boldsymbol{u}_{t}$ is an $N \times 1$ vector of disturbances, and all other variables are as previously defined. Once $\xi$ has been added in equation 5 , the spatial weight matrix could be treated as exogenous ( $\mathrm{Qu}$, Wang, and Lee 2016). This is because the unobserved factors that may affect both the spatial weight matrix and SCC are now captured by $\xi$, implying that the spatial weight matrix is not anymore correlated with $\boldsymbol{u}_{\boldsymbol{t}}$. Therefore, we would expect that $\xi$ significantly affects SCC.

\section{Data and Empirical Issues}

The data set used in this study was drawn from the Agricultural Financial Advisor (AgFA) database managed by the University of Wisconsin-Madison Center for Dairy Profitability. It is a balanced ${ }^{7}$ panel of 83 specialized dairy farms for the period

\footnotetext{
${ }^{5}$ In technical terms, $\epsilon_{t}$ from equation 1 is correlated with $\xi_{t}$ from equation 4 . For a formal exposition of the endogeneity problem of spatial weight matrices that are specified in terms of economic variables and the way to solve for such endogeneity, see Qu, Wang, and Lee (2016).

${ }^{6}$ As in equation 1 , the Hausman test is used to check whether $\eta$ represents a fixed or a random effect.

${ }^{7}$ Balanced panels are almost exclusively used in spatial econometric studies analyzing panel data sets. In this way, restrictive assumptions on why data are missing and debatable methods for recovering them (e.g., data imputation) can be avoided.
} 
2014-2017. These farms are operating in three contiguous counties, namely Sheboygan, Manitowoc, and Kewaunee, which stand out as having by far the highest proportion of farms in the database. Focusing on these counties ensures that each sample farmer has a considerable number of neighboring farmers. ${ }^{8}$

Data available include financial and production information as well as information on the exact location of the dairy farms in the form of farm coordinates. Information on SCC is available at the herd level (herd average) and measured in cells per ml. As explained earlier, SCC is an indicator of mastitis. It is widely accepted that most contagious mastitis is transmitted by fomites (e.g., milkers' hands, the milking unit, and udder wash cloths) from infected to non-infected animals during the milking process. The recommendations to decrease/control mastitis normally include management practices within the farm such as equipment cleaning, proper milking procedure, good beds for the cows, cleanliness of facilities, etc. Our selection of factors $(X)$ that may influence SCC is based on data availability and previous research on determinants of SCC (Dong, Hennessy, and Jensen 2012; Volpe et al. 2015). These factors include the following: herd size, summer precipitation and temperature, debt-to-asset ratio, non-farm income, and farm subsidies. Herd size is measured by the number of cows in an operation. The summer temperature and precipitation variables were constructed using the Parameter-Elevation Regressions on Independent Slopes Model (PRISM) maps (http://www.prism.oregonstate.edu/). Following Qi, Bravo-Ureta, and Cabrera (2015), summer in Wisconsin was defined as the months of June through September. Farm coordinates were then used to generate farm-specific average temperature and precipitation for the summer months that a farm is present in the panel. Debt-to-asset ratio is measured as the total debt a farm holds divided by its total assets. Non-farm income is a dummy variable assigned a value of one if the farmer earned income from nonagricultural activities, and zero otherwise. Finally, subsidies include all government payments received by farmers, including those relating to crop and livestock production and conservation. All SCC determinants $(\mathrm{X})$ are used in logarithmic form in equations 1 and 5, except for non-farm income.

The profit per cow variable that is used in the construction of $W_{t}^{i n v \_s}$ and in the instrumental variable approach (equation 4) is defined as the value of production less total operating costs and is expressed per livestock unit. Twenty two percent of the observations in our sample have negative profit per cow. To avoid deleting these observations from the analysis, the inverse hyperbolic sine transformation (arcsinh) is used: $\tilde{\Pi}_{i t}=\operatorname{arcsinh}\left(\Pi_{i t}\right)=\ln \left(\Pi_{i t}+\sqrt{\Pi_{i t}^{2}+1}\right) \cdot{ }^{9}$ The instruments used in equation 4 are the natural logarithm of the farm-level milk price and the use of a total mixed ration (TMR) feeding system. Milk price is measured in dollars per hundredweight. TMR is a dummy variable that takes the value of one if a farmer uses TMR to feed his/her cows, and zero otherwise. TMR is normally a long-standing farm decision. Farmers who elected it, will go with it for the foreseeable future. Simple descriptive statistics shows that farmers using TMR do not switch to a non-TMR feeding strategy during the sample period. Therefore, the use of TMR appears unaffected by unobserved

\footnotetext{
${ }^{8}$ See the results section for a discussion of neighborhood links.

${ }^{9}$ This transformation is often used in the literature to consider the logarithm of zero or negative values (see for e.g., Minviel and Sipiläinen 2018).
} 
factors and stochastic shocks. The employed instruments are assumed to determine farm profitability and, at the same time, have no direct impact on SCC. ${ }^{10,11}$

Milk price is a valid instrument because (a) it is not a choice variable and therefore unambiguously exogenous, (b) has a strong and statistically significant effect on farm profitability (Table A1), and (c) it does not have a direct effect on SCC (i.e., it affects SCC only through its effect on farm profitability (e.g., higher milk prices may lead to greater profitability which, in turn, increases a farmer's ability to invest in technologies and practices that reduce SCC)). While SCC levels can affect milk price through premiums and penalties imposed by milk buyers, such an effect is not confirmed in the present study. Correlation analysis revealed an insignificant relationship between SCC and milk price $(\mathrm{r}=-0.026, \mathrm{p}=0.633)$. Consistently, linear regression did not show an influence of SCC on milk price $\left(\beta=-1.408 \times 10^{-6}, \mathrm{p}=0.633\right)$.

Note that the employed estimation technique that corrects for the potential endogeneity of $W_{t}^{i n v s}$ is not a conventional two-stage least squares (2SLS) approach, where the predicted value of the endogenous variable is used in the second-stage model. Under such an approach, and in the event that SCC affects milk price, the predicted value of profit from equation 4 (which would contain the milk price variable) could cause a simultaneity problem when included in equation 5 as an additional explanatory variable. In the contrary, the error term of the first-stage equation (equation 4) is used as an additional explanatory variable in the second-stage model (equation 5) to account for unobserved time-varying factors that might affect both SCC and farm profitability. Hence this procedure as described in $\mathrm{Qu}$, Wang, and Lee (2016) provides a valid way of correcting for endogeneity.

Concerning the $W^{i n v}$ matrix, the distance cut-off $d^{*}$ was set to $25 \mathrm{~km}$ which is the minimum distance that guarantees at least one neighbor to each farmer. To address concerns about the robustness of our results to changes in $d^{*}$, we estimate models with 35,45 , and $55 \mathrm{~km}$ cut-off.

Table 1 presents a summary statistics of the variables used in the analysis. All monetary variables were deflated to 2014 \$ using appropriate price indices retrieved from the National Agricultural Statistics Service database.

\section{Results}

Before we start discussing the results of the empirical models considered in this article, we discuss neighborhood links. Sample farmers have, on average, 29 neighbors within a $25 \mathrm{~km}$ radius. On average, the minimum distance to neighboring farmers is $4.2 \mathrm{~km}$, with the shortest distance being $1.1 \mathrm{~km}$. Moving to the results of the estimated models, Table A1 in the appendix reports the first-step estimation results for the 2SIV model. All variables are highly significant with expected signs. ${ }^{12}$ The F-statistic for the joint significance of explanatory variables is greater than 10 , confirming that the selected

\footnotetext{
${ }^{10} \mathrm{We}$ avoid using a typical profit function (as for instance in Skevas, Wu, and Guan (2018)) for equation 4 , since profit determinants such as the value of farm machinery and equipment can have a direct impact on SCC.

${ }^{11}$ In their study examining the effect of different concentrate allocation strategies on the metabolic, inflammatory and immune profiles of cows, Little et al. (2018) found no relationship between feeding cows a TMR and the incidence of mastitis.

${ }^{12}$ We note that since a non-linear transformation of the dependent variable was used in the first stage of the 2SIV approach, the reported coefficients do not represent true marginal effects (Bellemare and Wichman 2020). The goal of this study is not to properly interpret the determinants of farm profit.
} 
Table 1. Summary Statistics of the Variables Used in the Analysis

\begin{tabular}{llrr}
\hline Variable & Unit & Mean & Std. Dev \\
\hline Somatic cell count & cells/mL & $192,738.60$ & $81,063.15$ \\
\hline Herd size & count & 235.99 & 310.92 \\
\hline Summer precipitation & inches & 3.82 & 0.49 \\
\hline Summer temperature & ${ }^{\circ}$ & 66.75 & 1.49 \\
\hline Debt-to-asset ratio & ratio & 0.25 & 0.20 \\
\hline Non-farm income & $(0 / 1)$ & 0.61 & 0.49 \\
\hline Subsidies & $\$ /$ hundredweight (cwt) & 0.25 & 0.41 \\
\hline Profit & $\$ /$ cow & 582.99 & 858.38 \\
\hline Milk price & $\$ /$ cwt & 19.47 & 4.34 \\
\hline Total mixed ration & $(0 / 1)$ & 0.43 & 0.50 \\
\hline
\end{tabular}

instruments are sufficiently strong (Stock and Watson 2015). Table 2 presents the estimation results from modeling the determinants of SCC. To recall, we estimate and compare three models: (a) a non-spatial OLS model, (b) an SLX model where neighborhood is defined in the dimension of geographic space (hereafter referred to as the SLX-inverse distance), and (c) an SLX model where physical proximity to more profitable farmers is used to capture potential linkages between neighboring farmers (hereafter referred to as the $\left.2 \mathrm{SIV}-W^{i n v_{-} s}\right)$. Since using spatial weight matrices based on different cut-off distances did not change our findings significantly, we present the results from the different spatial models with a $25 \mathrm{~km}$ distance cut-off (the remaining results are available from the authors upon request). The results of the Hausman tests suggest that fixed effects estimates are preferred to random effect estimates. Therefore, the results presented in Table 2 are those of the fixed effects models.

Notice that the estimated coefficients and their significance levels of the nonspatially lagged variables (upper half of Table 2) do not differ significantly across the different model specifications. Hence, the interpretation of these coefficients applies to all models that are presented in Table 2.

SCC is related significantly to two variables: herd size, and summer precipitation. Larger farms in terms of herd size are found to have lower SCC. More specifically, a 1 percent increase in herd size leads, on average, to a decrease in SCC between 0.33 to 0.39 percent. A reason for this finding may be that larger farms have more expertise in detecting, preventing, and controlling mastitis than smaller farms. Large farms may also have more financial resources to adopt new technologies and farm management practices that can reduce SCC (e.g., milk recording). This result is in line with the studies by Volpe et al. (2015) and Oleggini, Ely, and Smith (2001) who found a negative relationship between herd size and SCC in U.S. dairy farming. An increase in precipitation during the summer months is found to increase SCC. Increased summer rainfall contributes to high humidity which is known to be related to mastitis infection (Morse et al. 1988).

Rather we want to use the residuals of the profit function to address endogeneity in the second stage of the 2SIV approach. 
Table 2. Regression Results for the Non-spatial and SLX Models

\begin{tabular}{|c|c|c|c|c|c|c|}
\hline & \multicolumn{2}{|c|}{ Non-spatial model } & \multicolumn{2}{|c|}{ SLX-inverse distance } & \multicolumn{2}{|c|}{2 SIV-Winv_s } \\
\hline & Coef. & p-value & Coef. & p-value & Coef. & $\mathrm{p}$-value \\
\hline Herd size & -0.350 & 0.002 & -0.331 & 0.004 & -0.392 & 0.001 \\
\hline Summer precipitation & 0.331 & 0.001 & 0.362 & 0.000 & 0.304 & 0.003 \\
\hline Summer temperature & -0.201 & 0.180 & -0.151 & 0.622 & -0.144 & 0.410 \\
\hline Debt-to-asset ratio & -0.214 & 0.505 & -0.193 & 0.559 & -0.253 & 0.458 \\
\hline Non-farm income & -0.004 & 0.384 & -0.003 & 0.447 & -0.004 & 0.356 \\
\hline Subsidies & 0.058 & 0.265 & 0.012 & 0.840 & 0.035 & 0.537 \\
\hline W_Herd size & - & - & -0.036 & 0.175 & -0.093 & 0.079 \\
\hline W_Debt-to-asset ratio & - & - & -0.097 & 0.003 & -0.038 & 0.366 \\
\hline W_Non-farm income & - & - & -0.003 & 0.355 & 0.014 & 0.349 \\
\hline W_Subsidies & - & - & -0.008 & 0.432 & 0.022 & 0.082 \\
\hline Residuals & - & - & - & - & 0.122 & 0.000 \\
\hline AIC & -254.63 & - & -256.01 & - & -260.84 & - \\
\hline
\end{tabular}

Note: Bold font denotes statistically significant variables. AIC stands for Akaike's Information Criterion. Spatially lagged variables are denoted with a leading "W_". All continuous variables are in logs. 
We now turn to the interpretation of the effect of the spatially lagged explanatory variables on SCC (lower half of Table 2). ${ }^{13}$ Both spatial models include statistically significant spatially lagged covariates, implying that peer effects do play a role in explaining farm-level SCC. There are, however, differences across the employed spatial models in terms of the significance of peer effects. As expected, and in line with previous research (Läpple and Kelley 2015; Mourao 2019) indirect effects (i.e., the coefficients of the spatially lagged variables) are smaller in magnitude than the respective direct effect estimates. This is because they reflect cumulative spillovers from all farmers within the distance cut-off. ${ }^{14}$

Of the spatially lagged variables included in the SLX-inverse distance model, only debt-to-asset ratio is found to be a statistically significant predictor of SCC. More specifically, a (cumulative) 1 percent increase in neighboring farmers' debt-to-asset ratio decreases SCC by about 0.1 percent. This implies that farmers that have more indebted neighbors have cows with lower SCC. Highly indebted farms may have recently invested in management practices and technologies that decrease SCC. Nearby farmers may learn from these investments, and adopt similar technologies on their own farms.

Regarding the spatially lagged variables of the $2 \mathrm{SIV}-W^{\text {inv }-s}$ model, two were found to be significant predictors of SCC: herd size, and subsidies. The spatial lag of the herd size variable has a negative effect on SCC. More specifically, a (cumulative) 1 percent increase in neighbors' herd size decreases SCC by about 0.1 percent, likely pointing to the existence of a learning effect between large farms and their neighbors. Large farms have more resources at their disposal to invest in new technologies and management practices that reduce SCC. Nearby farmers could learn about the effectiveness of these new technologies and practices in reducing SCC, for example, by communicating with their neighbors, and modifying their strategies accordingly to better deal with mastitis prevention and control. More studies in the literature report the existence of spatial spillovers between large farmers and their neighbors (Läpple et al. 2017; Storm, Mittenzwei, and Heckelei 2014). Note that unlike in the 2SIV- $W^{i n{ }_{-} s}$ model, the spatially lagged herd size variable is statistically insignificant in the SLX-inverse distance model. An explanation for this difference may be that neighboring large farmers (in terms of herd size) are not necessarily the most efficient ones in reducing mastitis. Reduced mastitis incidence should be reflected in higher farm profitability as it often entails lower production costs and milk price bonuses. Therefore, the largest and at the same time more profitable farms are expected to have lower SCC and exert a greater influence on neighboring farms than large farms alone. Indeed, a closer look of the data shows that the top 25 percent of the largest farms (in terms of herd size) in our sample have, on average, 10 percent higher SCC scores than the top 25 percent of the most profitable farms in the same subset of largest farms. Moving to the interpretation of the spatially lagged subsidy variable, farmers surrounded by neighboring peers that receive high subsidy income are found to have cows with higher SCC. High subsidies may induce farmers to substitute farm income with subsidy income and expend less effort in implementing management practices that lower the incidence and severity of mastitis. Nearby farmers may mimic their neighbors' behavior and experience increases in mastitis incidence. Finally, the residuals from the first-step estimation are

\footnotetext{
${ }^{13}$ The spatially lagged precipitation and temperature variables are excluded from the model specification because climatic conditions are relatively homogeneous within a $25 \mathrm{~km}$ radius.

${ }^{14}$ These spillovers depend on the number of farmers within the distance cut-off and decline with distance.
} 
significant at the 1 percent level, giving strong support that farm profitability is the

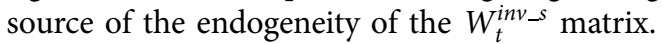

Finally, among all the employed models, the AIC (bottom of Table 2) favors the $2 S I V-W^{i n v s}$ model. That is, the data favor the model in which spatial effects are defined in terms of both geographic proximity and farm profitability.

\section{Conclusions}

Using a panel dataset of 83 Wisconsin dairy farms over the period 2014-2017, this article examines the factors influencing average herd somatic cell count (SCC). We specifically explore whether and to what extent spatial spillovers affect SCC, making it the first article to link SCC with peer influence. Moreover, unlike previous studies that examine the role of spatial spillovers on farm decision-making and performance, we examine whether defining the neighborhood space both in terms of physical proximity and farm profitability gives rise to spatial spillovers.

The findings from this article indicate that SCC is not only affected by own-farm decisions and characteristics but also by those of neighboring farms. This result implies that future work aiming at exploring the determinants of SCC should test for and, if necessary, account for peer effects to make accurate inferences. We also find that farm profitability is an important driver of spatial spillovers among neighboring farms. Significant differences in the estimated spatial spillovers are observed when using farm profitability as well as physical proximity to define the neighborhood links, as opposed to using just physical proximity. Model comparison results show that defining the neighborhood space in terms of proximity to more profitable peers (as compared to physical proximity alone) improves model fit. One should keep in mind, however, that this result is case-specific. The construction of spatial weight matrices is an open and debatable question, and must be guided by theoretical considerations and represent as far as possible real social and economic phenomena (Corrado and Fingleton 2012). What can be learned from this article is that researchers should be aware that the choice of the spatial weight matrix can have a strong effect on the inferences made in regard to the effect of spatial spillovers on the variable of interest.

Results also provide useful clues about the channels through which spatial spillovers operate. These channels are: (a) neighboring large farmers, and (b) indirect effects of neighboring farmers' financial characteristics such as subsidies received. It is likely that these channels arise as a result of direct communication or influence between neighboring farmers on farm practices and decision-making. For example larger farms are often more likely to adopt agricultural innovations in order to reduce the occurrence of mastitis. Neighboring farmers may adopt similar technologies either because they interact with, and learn from large neighbors or from a desire to conform with peers' choices. Previous studies indeed show that Wisconsin dairy farms influence each other in decisions to adopt new practices (Lewis, Barham, and Robinson 2011).

Apart from spatial spillovers, this article also shows that direct (i.e., own-farm) effects affect SCC. More specifically, farmers operating large farms (in terms of herd size) are found to have cows with lower SCC. On the other hand, higher summer precipitation leads to an increase in SCC.

Considered together, these results provide direct and indirect paths for lowering farm-level SCC. In relation to direct paths, the presence of peer effects in the context of mastitis management imply potentially large social multiplier effects and economic gains related to reduced SCC through exchange of information between neighboring 
farmers on good management practices to control and prevent mastitis. Hence, strategies that promote peer interactions and learning effects might prove efficacious in reducing farm-level SCC. Such strategies may include field days, farm walks on farms that are efficient in reducing SCC, and discussion meetings. Regarding indirect paths, the fact that larger farms have lower SCC, and this positively impacts neighboring farms efforts to reduce SCC, implies that the generally observed trend in U.S. dairy sector of expanding and intensifying production may trigger further decreases in mastitis incidence and related economic losses.

Finally, while our findings provide quantitative support for the presence of spatial spillovers on neighboring farms' SCC and allow for judgments to be made regarding the channels through which these effects operate, further work is needed to provide behavioral insights of how these spillovers arise and if farmer-to-farmer information transfers and exchanges do happen in practice. Further work could also examine whether spatial spillovers arise as result of physical proximity to farmers of a similar income level. Such farmers may influence each other's behavior because they are likely to face comparable budget constraints and tackle similar problems.

Supplementary material. The supplementary material for this article can be found at https://doi.org/10. 1017/age.2020.22

Acknowledgments. The authors wish to thank the Center for Dairy Profitability at the University of Wisconsin-Madison and its Associate Director, Jenny Vanderlin, for providing the data and for useful discussions.

Conflicts of Interest. None.

\section{References}

Alarcon, P., B. Wieland, A.L. Mateus, and C. Dewberry. 2014. "Pig Farmers' Perceptions, Attitudes, Influences and Management of Information in the Decision-Making Process for Disease Control." Preventive Veterinary Medicine 116(3): 223-242.

Areal, F.J., K. Balcombe, and R. Tiffin. 2012. "Integrating Spatial Dependence Into Stochastic Frontier Analysis." Australian Journal of Agricultural and Resource Economics 56(4): 521-541.

Bellemare, M.F., and C.J. Wichman. 2020. "Elasticities and the Inverse Hyperbolic Sine Transformation." Oxford Bulletin of Economics and Statistics 82(1): 50-61.

Chatzimichael, K., M. Genius, and V. Tzouvelekas. 2014. "Informational Cascades and Technology Adoption: Evidence From Greek and German Organic Growers." Food policy 49(Part 1): 186-195.

Conley, T.G., and C.R. Udry. 2010. "Learning About A New Technology: Pineapple in Ghana." American Economic Review 100(1): 35-69.

Corrado, L., and B. Fingleton. 2012. "Where Is the Economics in Spatial Econometrics?" Journal of Regional Science 52(2): 210-239.

Delgado, F.J., S. Lago-Peñas, and M. Mayor. 2018. "Local Tax Interaction and Endogenous Spatial Weights Based on Quality of Life." Spatial Economic Analysis 13(3): 296-318.

Dong, F., D.A. Hennessy, and H.H. Jensen. 2012. "Factors Determining Milk Quality and Implications for Production Structure Under Somatic Cell Count Standard Modification." Journal of Dairy Science 95(11): 6421-6435.

Elhorst, J.P. 2001. "Dynamic Models in Space and Time." Geographical Analysis 33(2): 119-140.

Getis, A. 2009. "Spatial Weights Matrices." Geographical Analysis 41(4): 404-410.

Halasa, T., K. Huijps, O. Østerås, and H. Hogeveen. 2007. "Economic Effects of Bovine Mastitis and Mastitis Management: A Review." Veterinary Quarterly 29(1): 18-31.

Halleck Vega, S., and J.P. Elhorst. 2015. "The SLX Model." Journal of Regional Science 55(3): 339-363.

Haskell, M., F. Langford, M. Jack, L. Sherwood, A. Lawrence, and K. Rutherford. 2009. "The Effect of Organic Status and Management Practices on Somatic Cell Counts on UK Dairy Farms." Journal of Dairy Science 92(8): 3775-3780. 
Hogeveen, H., W. Steeneveld, and C.A. Wolf. 2019. "Production Diseases Reduce the Efficiency of Dairy Production: A Review of the Results, Methods, and Approaches Regarding the Economics of Mastitis." Annual Review of Resource Economics 11: 289-312.

Holloway, G., and M.L.A. Lapar. 2007. "How Big Is Your Neighbourhood? Spatial Implications of Market Participation Among Filipino Smallholders." Journal of Agricultural Economics 58(1): 37-60.

Kelejian, H.H., and I.R. Prucha. 2010. "Specification and Estimation of Spatial Autoregressive Models With Autoregressive and Heteroskedastic Disturbances." Journal of Econometrics 157(1): 53-67.

Kuiper, D., Jansen, J, Renes, R., Leeuwis, C, and Van der Zwaag, H. (2005). "Social Factors Related to Mastitis Control Practices: The Role of Dairy Farmers' Knowledge, Attitude, Values, Behaviour and Networks". 4th IDF International Mastitis Conference, by H. Hogeveen. Maastricht, NL. Wageningen Academic Publishers, Wageningen, NL, 576-582.

Läpple, D., G. Holloway, D.J. Lacombe, and C. O’Donoghue. 2017. "Sustainable Technology Adoption: A Spatial Analysis of the Irish Dairy Sector." European Review of Agricultural Economics 44(5): 810-835.

Läpple, D., and H. Kelley. 2015. "Spatial Dependence in the Adoption of Organic Drystock Farming in Ireland." European Review of Agricultural Economics 42(2): 315-337.

Lewis, D.J., B.L. Barham, and B. Robinson. 2011. "Are There Spatial Spillovers in the Adoption of Clean Technology? the Case of Organic Dairy Farming." Land Economics 87(2): 250-267.

Little, M.W., G.A. Arnott, M.D. Welsh, J.P. Barley, N.E. O'Connell, and C.P. Ferris. 2018. Comparison of Total-Mixed-Ration and Feed-To-Yield Strategies on Blood Profiles and Dairy Cow Health. Veterinary Record:vetrec-2017.

Maertens, A., and C.B. Barrett. 2012. "Measuring Social Networks' Effects on Agricultural Technology Adoption." American Journal of Agricultural Economics 95(2): 353-359.

Marasteanu, I.J., and E.C. Jaenicke. 2016. "Hot Spots and Spatial Autocorrelation in Certified Organic Operations in the United States." Agricultural and Resource Economics Review 45(3): 485-521.

Minviel, J.J., and T. Sipiläinen. 2018. "Dynamic Stochastic Analysis of the Farm Subsidy-Efficiency Link: Evidence From France." Journal of Productivity Analysis 50(1-2): 41-54.

Morse, D., M. DeLorenzo, C. Wilcox, R.J. Collier, R. Natzke, and D. Bray. 1988. "Climatic Effects on Occurrence of Clinical Mastitis." Journal of Dairy Science 71(3): 848-853.

Mourao, P.R. 2019. "Keeping up With the (Portuguese) Joneses'-A Study on the Spatial Dependence of Municipal Expenditure." Applied Economics 51(34): 3689-3709.

Oleggini, G., L. Ely, and J. Smith. 2001. "Effect of Region and Herd Size on Dairy Herd Performance Parameters." Journal of Dairy Science 84(5): 1044-1050.

Qi, L., B. Bravo-Ureta, and V. Cabrera. 2015. "From Cold to Hot: Climatic Effects and Productivity in Wisconsin Dairy Farms." Journal of Dairy Science 98(12): 8664-8677.

Qu, X., X. Wang, and L.-F. Lee. 2016. "Instrumental Variable Estimation of A Spatial Dynamic Panel Model With Endogenous Spatial Weights When T Is Small." The Econometrics Journal 19(3): 261-290.

Rogers, E.M. 2010. Diffusion of innovations (4th edition). New York: Simon and Schuster Inc.

Skevas, I. 2020. "Inference in the Spatial Autoregressive Efficiency Model with an Application to Dutch Dairy Farms." European Journal of Operational Research 283(1): 356-364.

Skevas, T., and J. Grashuis. 2020. "Technical Efficiency and Spatial Spillovers: Evidence From Grain Marketing Cooperatives in the US Midwest." Agribusiness 36(1): 111-126.

Skevas, T., I. Skevas, and S.M. Swinton. 2018. "Does Spatial Dependence Affect the Intention to Make Land Available for Bioenergy Crops?” Journal of Agricultural Economics 69(2): 393-412.

Skevas, T., F. Wu, and Z. Guan. 2018. "Farm Capital Investment and Deviations From the Optimal Path." Journal of Agricultural Economics 69(2): 561-577.

Stock, J.H., and M.W. Watson. 2015. Introduction to econometrics (3rd Ed.). Hoboken, NJ: Pearson Education, Inc..

Storm, H., K. Mittenzwei, and T. Heckelei. 2014. "Direct Payments, Spatial Competition, and Farm Survival in Norway." American Journal of Agricultural Economics 97(4): 1192-1205.

Tobler, W.R. 1970. “A Computer Movie Simulating Urban Growth in the Detroit Region.” Economic geography 46(sup1): 234-240.

Volpe, R.J., T.A. Park, F. Dong, and H.H. Jensen. 2015. "Somatic Cell Counts in Dairy Marketing: Quantile Regression for Count Data." European Review of Agricultural Economics 43(2): 331-358. 


\section{Appendix}

Table A1. Empirical Results for the First Stage of the 2SIV Approach

\begin{tabular}{lcc}
\hline Variable & Coef. & p-value \\
\hline Constant & -6.655 & 0.000 \\
\hline Milk price & 2.608 & 0.016 \\
\hline Total mixed ration & 0.495 & 0.000 \\
\hline F-statistic & 17.60 & 0.000 \\
\hline
\end{tabular}

Note: The Hausman test favors the fixed effect model. Milk price squared was initially tested for but was found insignificant and therefore excluded from the final model.

Cite this article: Skevas T, Skevas I, Cabrera VE (2021). Farm Profitability as a Driver of Spatial Spillovers: The Case of Somatic Cell Counts on Wisconsin Dairies. Agricultural and Resource Economics Review 50, 187-200. https://doi.org/10.1017/age.2020.22 